\title{
L. On the cause of remarkably mild winters which occasionally occur in England
}

\author{
Lieut.-Colonel Edward Sabine R.A. For. Sec. R.S.
}

To cite this article: Lieut.-Colonel Edward Sabine R.A. For. Sec. R.S. (1846) L. On the cause of remarkably mild winters which occasionally occur in England, Philosophical Magazine Series 3, 28:187, 317-324, DOI: $10.1080 / 14786444608645087$

To link to this article: http://dx.doi.org/10.1080/14786444608645087

曲 Published online: 30 Apr 2009.

Submit your article to this journal $₫$

Џll Article views: 2

Q View related articles $\square$ 
means of causing light to evolve electricity and magnetism, are thoughts continually pressing upon the mind; but it will be better to occupy both time and thought, aided by experiment, in the investigation and development of real truth, than to use them in the invention of suppositions which may or may not be founded on, or consistent with fact.

Royal Institution, Oct. 29, 1845.

L. On the Cause of remarkably Mild Winters which occasionally occur in England. By Lieut.-Colonel SABINE, R.A., For. Sec. R.S.

\section{To the Editors of the Philosophical Magazine and Journal. Gentriemen,}

THE unusual character of the winter which we have just 1 experienced, together with its effects which we are now witnessing upon our gardens and fields, and its influence on the public health as evidenced by the bills of mortality, should make it an object not only of scientific, but of general interest, to endeavour to trace out the cause of so remarkable a phænomenon. By a memorandum with which the Astronomer Royal has been so obliging as to furnish me, it appears that the mean temperature in December, January and February, exceeded the mean temperature of the same months in the preceding year by the amounts respectively of $8^{0} \cdot 7,5^{\circ} \cdot 3$, $11^{\circ} \cdot 2$; on an average above $8^{\circ}$ for three months. An excess of temperature of such amount and such continuance, must surely, one would suppose, have some sufficiently notable cause. I am not aware that any probable cause has yet been suggested; but should you oblige me by inserting this communication, it may at least be of use in commencing the discussion, and possibly in eliciting the opinions of others, whose views on the subject the public may naturally desire to know.

The winter which within my recollection most nearly resembled the present, was that of 1821-1822, and undoubtedly the resemblance is in many respects very striking. For the peculiarity in that year there was a cause assigned, adequate I believe to account for all the phænomena, and of which the existence was proved: I allude to the extension of the Gulfstream in that year to the coast of Europe, instead of jts terminating as it usually does about the meridian of the Azores. In the winter of 1821-1822, the warm water of the Gulf-stream spread itself beyond its usual bounds over a space of ocean which may be roughly estimated as exceeding 600 miles in latitude and 1000 in longitude, carrying with it water several de- 


\section{Lieut.-Col. Sabine on the Cause of Mild Winters}

grees higher than the temperature of the sea in ordinary years in the same parallels. The facts, both in respect to the Gulfstream, and to the peculiarities of the winter in that year, were stated in the volume of Pendulum and other observations which I published in 1825 ; perhaps the statement of them now will be most satisfactorily given in the words which were then used: and I have the less hesitation in introducing an extract from that work, because it was published many years ago, and is, I believe, but little known, at least in this country. The statement was as follows:-

"In the passage of the Iphigenia from England to the coast of Africa, a remarkable and very interesting evidence was obtained, by observations on the temperature of the sea, of the accidental presence in that year of the water of the Gulfstream, in longitudes much to the eastward of its ordinary extension.

"The Iphigenia sailed from Plymouth on the 4th of January [1822], after an almost continuous succession of very heavy westerly and south-westerly gales, by which she had been repeatedly driven back and detained in the ports of the Channel; the following memorandum exhibits her position at noon on each day of her subsequent voyage from Plymouth to Madeira, and from thence to the Cape Verd Islands, the temperature of the air in the shade and to windward, and that of the surface of the sea; it also exhibits in comparison, the ordinary temperature of the ocean at that season, in the respective parallels, which Major Rennell has been so kind as to permit me to insert on his authority, as an approximation founded on his extensive inquiries; the last column shows the excess or defect in the temperature observed in the Iphigenia's passage.

\begin{tabular}{|c|c|c|c|c|c|c|c|}
\hline \multirow{2}{*}{\multicolumn{2}{|c|}{ Date. }} & \multirow{2}{*}{ Latitude $\mathrm{N}$. } & \multirow{2}{*}{ Longitude $\mathbf{W}$} & \multirow{2}{*}{ Air. } & \multicolumn{2}{|c|}{ Surface-water. } & \multirow{2}{*}{$\begin{array}{l}\text { Excess or } \\
\text { defect. }\end{array}$} \\
\hline & & & & & Observed. & Usual. & \\
\hline $\begin{array}{l}\text { Madeira to } \\
\text { Cape Verd } \\
\text { lslands. }\end{array}$ & Tlan. & $\begin{array}{ll}47 & 30 \\
44 & 20 \\
41 & 22 \\
38 & 54 \\
\text { No } & \text { obser } \\
33 & 40 \\
26 & 00 \\
24 & 30 \\
23 & 06 \\
21 & 02 \\
19 & 20\end{array}$ & \begin{tabular}{|rr}
7 & 30 \\
9 & 30 \\
11 & 37 \\
13 & 20 \\
vation. \\
15 & 30 \\
17 & 50 \\
18 & 50 \\
20 & 00 \\
21 & 27 \\
23 & 00
\end{tabular} & $\begin{array}{l}47 \cdot 0 \\
52 \cdot 5 \\
54 \cdot 0 \\
54 \cdot 2 \\
56 \cdot 0 \\
60 \cdot 7 \\
66 \cdot 0 \\
68 \cdot 0 \\
69 \cdot 0 \\
69 \cdot 5 \\
70 \cdot 6\end{array}$ & $\begin{array}{l}49 \cdot 0 \\
55 \cdot 7 \\
58 \cdot 2 \\
61 \cdot 7 \\
63 \cdot 0 \\
64 \cdot 0 \\
65 \cdot 5 \\
67 \cdot 0 \\
69 \cdot 0 \\
69 \cdot 5 \\
70 \cdot 2\end{array}$ & \begin{tabular}{|l}
$\mathbf{5 0} \cdot 0$ \\
$\mathbf{5 2 \cdot 5}$ \\
$\mathbf{5 4} \cdot 0$ \\
$55 \cdot 7$ \\
$58 \cdot 0$ \\
$60 \cdot 0$ \\
$67 \cdot 0$ \\
$68 \cdot 4$ \\
$69 \cdot 5$ \\
$71 \cdot 2$ \\
$71 \cdot 6$
\end{tabular} & $\begin{array}{l}-1 \\
+3 \cdot 2 \\
+4.2 \\
+6 \\
+5 \\
+4 \\
-1.5 \\
-1.4 \\
-0.5 \\
-1.7 \\
-1.4\end{array}$ \\
\hline
\end{tabular}


"It is seen by the preceding memorandum, that in the passage from Plymouth to Madeira, the Iphigenia found the temperature of the sea, between the parallels of $44 \frac{1}{3}^{\circ}$ and $33 \frac{2}{3}^{\circ}$, several degrees warmer than its usual temperature in the same season; namely $3^{\circ} \cdot 2$ in $44 \frac{1}{3}^{\circ}$, increasing to $6^{\circ}$ in $39^{\circ}$, and again diminishing to $4^{\circ}$ in $33 \frac{2}{3}^{\circ}$; whilst at the same period, the general temperature of the ocean in the adjoining parallels, both to the northward and to the southward, even as far as the Cape Verd Islands in $19^{2} \frac{2}{3}^{\circ}$, was colder by a degree and upwards than the usual average. The evidence of many careful observers at different seasons and in different years, whose observations have been collected and compared by Major Rennell, has satisfactorily shown, that the water of the Gulfstream, distinguished by the high temperature which it brings from its origin in the Gulf of Mexico, is not usually found to extend to the eastward of the Azores. Vessels navigating the ocean between the Azores and the continent of Europe, find at all seasons a temperature progressively increasing as they approach the sun; the absolute amount varies according to the season, the maximum in summer being about $14^{\circ}$ warmer than the maximum in winter; but the progression in respect to latitude is regular, and is nearly the same in winter as in summer, being an increase of $3^{\circ}$ of Fahr. for every $5^{\circ}$ of latitude. It is further observed, that the ordinary condition of the temperature, in the part of the ocean under notice, is little subject to disturbance, and that in any particular parallel and season, the limits of variation in different years are very small; after westerly winds of much strength or continuance, the sea in all the parallels is rather colder than the average temperature, on account of the increased velocity communicated to the general set of the waters of the north-eastern Atlantic towards the south. To the heavy westerly gales which had prevailed almost without intermission in the last fortnight in November, and during the whole of December, may therefore be attributed the colder temperatures observed in the latitude of $47 \frac{1}{2}^{\circ}$, and in those between $26^{\circ}$ and $19 \frac{1}{3}^{\circ}$. .

"If doubt could exist in regard to the higher temperatures between $44 \frac{1}{3}^{\circ}$ and $33^{\circ}$ being a consequence of the extension in that year of the Gulf-stream in the direction of its general course, it might be removed by a circumstance well-deserving of notice, namely, that the greatest excess above the natural temperature of the ocean was found in or about the latitude of $39^{\circ}$, being the parallel where the middle of the stream, indicated by the warmest water, would arrive, by continuing to flow to the eastward of the Azores, in the prolongation of the great circle in which it is known to reach the mid-Atlantic. 


\section{Lieut.-Col. Sabine on the Cause of Mild Winters}

"One previous and similar instance is on record, in which the water of the Gulf-stream was traced by its temperature quite across the Atlantic to the coast of Europe ; this was by Dr. Franklin, in a passage from the United States to France, in November $1776^{*}$. The latter part of his voyage, $i . e$. from the meridian of $35^{\circ}$ to the Bay of Biscay, was performed, with little deviation, in the latitude of $45^{\circ}$; in this run exceeding 1200 miles, in a parallel of which the usual temperature, towards the close of November, is about $55 \frac{1}{2}^{\circ}$, he found $63^{\circ}$ in the longitude of $35^{\circ} \mathrm{W}$, diminishing to $60^{\circ}$ in the Bay of Biscay; and $61^{\circ}$ in $10^{\circ}$ west longitude, near the same spot where the Iphigenia found $55^{\circ} .7$ on the 6th of January, being about five weeks later in the season. At this spot then, where the Iphigenia crossed Dr. Franklin's track, the temperature in November 1776 was $5 \frac{1}{2}^{\circ}$, and in January $1822,3^{\circ} \cdot 2$ above the ordinary temperature of the season.

"There can be little hesitation in attributing the unusual extension of the stream in particular years to its greater initial velocity, occasioned by a more than ordinary difference in the levels of the Gulf of Mexico and of the Atlantic; it has been computed by Major Rennell, from the known velocity of the stream at various points of its course, that in the summer months, when its rapidity is greatest, the water requires about eleven weeks to run from the outlet of the Gulf of Mexico to the Azores, being about 3000 geographical miles; and he has further supposed, in the case of the water of which the temperature was examined by Dr. Franklin, that perhaps not less than three months were occupied, in addition, by its passage to the consts of Europe, being altogether a course exceeding 4000 geographical miles. On this supposition, the water of the latter end of November 1776 may have quitted the Gulf of Mexico, with a temperature of $83^{\circ}$, in June; and that of January 1822, towards the end of July, with nearly the same temperature. The summer months, particularly July and August, are those of the greatest initial velocity of the stream, because it is the period when the level of the Caribbean Sea and Gulf of Mexico is most deranged.

"It is not difficult to imagine that the space between the Azores and the coasts of the old continent, being traversed by the stream, slowly as it must be, at a much colder season in the instance observed by the Iphigenia than in that by Dr. Franklin, its temperature may have been cooled thereby to a nearer approximation to the natural temperature of the ocean in the former than in the latter case; and that the difference

* Franklin's Works, 8vo, London, 1806, vol. ii. pp. 200, 201. 
between the excess of $5^{\circ} .5$ in November, and of $3^{\circ} \cdot 2$ in January, may be thus accounted for.

"If the explanation of the apparently very unusual facts observed by Dr. Franklin in 1776, and by the Iphigenia in 1822, be correct, how highly curious is the connexion thus traced between a more than ordinary strength of the winds within the tropics in the summer, occasioning the derangement of the level of the Mexican and Caribbean seas, and the high temperature of the sea between the British Channel and Madeira, in the following winter!

"Nor is the probable meteorological influence undeserving of attention, of so considerable an increase in the temperature of the surface water over an extent of ocean exceeding 600 miles in latitude and 1000 in longitude, situated so importantly in relation to the western parts of Europe. It is at least a remarkable coincidence, that in November and December 1821, and in January 1822, the state of the weather was so unusual in the southern parts of Great Britain and in France, as to have excited general observation; in the meteorological Journals of the period it is characterized as ' most extraordinarily hot, damp, stormy, and oppressive ;' it is stated, ' that an unusual quantity of rain fell both in November and December, but particularly in the latter ;' that ' the gales from the west and south-west were almost without intermission,' and that in December, the mercury in the barometer was lower than it had been known for thirty-five years before*."

* "The following description of this very remarkable winter is extracted from Mr. Daniell's Essay on the Climate of London (Meteorological Essays. London, 1823, pages 297 and 298), and becomes lighly curious when viewed in connexion with the unusual temperature of the ocean in the direction in which the principal winds proceeded.

"November 1821 differed from the mean, and from both the preceding years, in a very extraordinary way. The average temperature was $5^{\circ}$ above the usual amount; and although its dryness was in excess" (the relative dryness in consequence of the increased temperature) " the quantity of rain exceeded the mean quantity by one-half. The barometer on the whole was not below the mean. All the low lands were flooded, and the sowing of wheat very much interrupted by the wet.

" In December the quantity of rain was very nearly double its usual amount. The barometer averaged considerably below the mean, and descended lower than had been known for thirty-five years. Its range was from 30.27 inches to $28 \cdot 12$ inches. The temperature was still high for the season, and the weather continued, as in the last month, in an uninterrupted course of wind and rain; the former of ten approaching to a hurricane, and the latter inundating all the low grounds. The warer-sodden state of the soil, in many parts, prevented wheat-sowing, or fallowing the land at the regular season. The mild temperature pushed forward all the earlysown wheats to a height and luxuriance scarcely ever before witnessed. The grass and every green production increased in an equal proportion.

"January, 1822. This most extraordinary season still continued above Phil. Mag. S. 3. Vol. 28. No. 187. April 1846. 


\section{Lieut.-Col. Sabine on the Cause of Mild Winters}

It is impossible to read this description of the winter of 1821-1822 without being struck with the many features which it has in common with that of the present year. The excess of heat in both amounted to several degrees, and continued through several months. There were similar floods in many parts of England in the early part and middle of this winter; and these were not confined to England only, but extended, as in 1821-1822, to many of the rivers of western Europe. The tension of the vapour conveyed to the shores of the British Channel in December, January and February last, was nearly $\frac{1}{3}$ rd part greater, as appears by the Greenwich Observations, than in the same months of the preceding year; although in consequence of the much higher temperature, the humidity of the air, or the ratio of the humidity to saturation, has been less. This was also the case in 1821-1822. We have had an unusual prevalence of westerly and south-westerly winds at the season when they are ordinarily replaced in a much greater proportion by the dry and cold winds which come to us from the interior of the great continents of Europe and Asia. If in the southern parts of Britain, and on the shores of the British Channel, we have been less severely affected by storms and extreme barometrical depressions than was the case in 1821-1822, we may possibly owe the comparative exemption to the fact that the excess of heat above the mean has been greater in the winter of 1845-1846 than it was in 1821-1822; whence we may infer perhaps that the conflict of the opposing currents of the atmosphere has been removed in the present year further to the north and north-east than on the former occasion; it is at the limits which are reached by the warm and humid current proceeding from the south-west, and in the localities where it encounters the dry and cold stream pressing from the east and north-east, that the greater atmospherical derangements are produced, and these have been experienced in the northern parts of Britain.

The similarity of the two winters having thus been shown, and specially their agreement in those features in which they differ from ordinary winters, it will naturally be asked, what evidence we have to prove or disprove an extension of the Gulf-

the mean temperature, but the rain, as if exhausted in the preceding month, fell much below the usual quantity in this. There was not one day on which the frost lasted during the twenty-four hours.

" "Serious apprehensions were entertained, lest the wheats, drawn up as they had been by the warm and moist weather, without the slightest check from frost, should be exhausted by excessive vegetation, and ultimately be more productive in straw than corn.

" The month of February, still $5^{\circ}$ above the mean temperature, ended a winter which never has been paralleled." 
stream in the present year, similar to that which took place in 1821. To this it must be replied, that strange as it may appear, this remarkable phænomenon may take place in any year without our having other knowledge of it than by its effects, although it occurs at so short a distance from our ports, from whence so many hundred vessels are continually crossing and recrossing the part of the ocean where a few simple observations with a thermometer would serve to make it known. We have no organized means of learning an occurrence which, whether it be or be not the cause of the present extremely mild winter, cannot fail whenever it does occur to affect materially and for a considerable length of time the climate of an extensive district of the globe including our own islands. History has recorded two instances in which the extension of the Gulf-stream is known to have taken place; and in both we owe our knowledge of it to the casual observations of an accidental voyager. Some one there may be in the present winter whose curiosity may have induced him, in the well-frequented passage between England and Madeira, to dip a thermometer in the sea once or twice a day, and who may therefore, perhaps unconsciously, be in possession of the very facts which it is desirable to know ; in such case this communication, should it meet his eye, may be the means of inducing their publication. It is desirable however that we should not be thus altogether dependent on accident for information which may have even greater practical than scientific value; happily it is well known that suggestions of this nature, when really deserving attention, do not pass unheeded by our excellent $\mathrm{Hy}$ drographer, to whose department such subjects seem naturally to belong*.

But not only might we by such means be occasionally informed in November or December that we had probably to expect a continuance of very mild weather through January and February; it is not unreasonable to suppose that such winters might well be anticipated at a still earlier period of the year; ships sail faster than the Gulf-stream flows, and a more than usual difference existing in the levels of the Gulf of Mexico and the Atlantic, or a more than usual initial velocity of the stream itself, with the consequent probability of a winter of unusual mildness in Europe, might be known in England in the summer or in the early autumn; or even going

* It is much to be wished that a society existed in England which should charge itself with the many interesting and important considerations belonging to physical geography. Did the object and scope of the Royal Geographical Society embrace physical as well as descriptive geography, it cannot be doubted that science and the public would be greatly benefited. 
back to a yet earlier stage of the phænomenon, we might be apprised that the causes which operate in producing the derangement of the level of the Caribbean and Mexican seas were prevailing in any particular year in an unusually high degree.

I wish in conclusion to guard against the possibility of being understood to suppose that amidst the variety of incidents by which our climate is affected, there may not be others which may be influential in the production of winters of unusual mildness in an equal, or even in a greater degree than the extension of the Gulf-stream; or, that whenever the stream reaches the coasts of Europe, its influence on our climate must necessarily occasion winters like that of 18211822 , or 1845-1846. It is reasonable to believe that there may be degrees of initial velocity between that which is usual and that which is extreme. There may also be counteracting or qualifying causes with which we are as yet wholly unacquainted. The object of this communication is rather to recall to recollection, on the occasion of the present remarkable winter, the coincidence that was discovered between the similar winter in 1821-1822, and the extension of the stream; and to promote the adoption of such simple means as may supply additional evidence, whereby we may discern between coincidence observed on a single occasion, and connexion which may be established by the observation of repeated coincidence.

Woulwich, March 17th, 1846. I am, Gentlemen, Your obedient Servant, Edward Sabine.

\section{Observations on the Recent Researches of Prof. Faraday. By M. Pouillet*.}

FOR some months past there has been much talk about a new series of researches by M. Faraday, the result of which was one of the most important discoveries, the action of magnetism on light. Two authentic documents have at length reached us on this subject; one is published in the January number of the Philosophical Magazine, being an abstract of the sitting of the Royal Society of the 27 th of November, the other was communicated at the last meeting of the French Academy by M. Dumas in the name of Mr. Faraday himself. Various results are announced in these two publications, but only one fact is presented with some development,

- Translated from the Comptes Rendus, for January 26, 1846.-The researches of Prof. Faraday, referred to in this paper, are given entire in our present Number. 